\title{
Combined Nicotinic and Muscarinic Blockade in Elderly Normal Volunteers: Cognitive, Behavioral, and Physiologic Responses
}

\author{
John T. Little, M.D., Douglas N. Johnson, Ph.D., Marcia Minichiello, M.A., \\ Herb Weingartner, Ph.D., and Trey Sunderland, M.D.
}

Establishing a pharmacologic model of the memory deficits
of Alzheimer's disease could be an important tool in
understanding how memory fails. We examined the
combined effects of the muscarinic antagonist scopolamine
and the nicotinic antagonist mecamylamine in eight normal
elderly volunteers (age $61.9 \pm 8.3$ yrs, SD). Each received
four separate drug challenges (scopolamine $(0.4 \mathrm{mg} I V)$,
mecamylamine ( $0.2 \mathrm{mg} / \mathrm{kg}$ up to $15 \mathrm{mg} P O)$,
mecamylamine + scopolamine, and placebo). There was a
trend toward increased impairment in explicit memory for
the mecamylamine + scopolamine condition as compared to

KEY WORDS: Scopolamine; Mecamylamine; Cognitive; Geriatrics; Muscarinic antagonist; Nicotinic antagonist

Given the limited animal models of Alzheimer's disease (AD) and other cognitive disorders, pharmacologic modeling of memory deficits in humans has been proposed as an approach that can be used to probe the neurochemistry of memory (Sunderland et al. 1986). Because there is abundant evidence that the cholinergic system is of special importance in $\mathrm{AD}$ (Davies and Verth 1978; Bowen et al. 1983; Coyle et al. 1983; Mash et

From the Geriatric Psychiatry Branch (JTL, MM, TS), National Institute of Mental Health, Bethesda, Maryland; and Section of Cognitive Neurosciences (HW), National Institute on Alcohol Abuse and Alcoholism, Bethesda, Maryland; and Department of Psychology (DNJ), Colgate University, Hamilton, New York, USA.

Address correspondence to: John T. Little, M.D., Western Psychiatric Institute and Clinic, 3811 O'Hara Street, Pittsburgh, PA 15213, USA.

Address reprint requests to: Trey Sunderland, M.D., NIMH, 10/ 3N228 MSC 1275, Bethesda, MD 20892, USA.

Received 10 December 1996; revised 8 October 1997; accepted 14 November 1997. scopolamine alone. Increased impairment was also seen for the mecamylamine + scopolamine condition as compared to scopolamine alone in selected behavioral ratings. Pupil size increased when mecamylamine was added to scopolamine, while systolic blood pressure and pulse changed in concordance with ganglionic blockade. These data together with previous brain-imaging results suggest that this muscarinic-nicotinic drug combination may better model Alzheimer's disease than either drug alone.

[Neuropsychopharmacology 19:60-69, 1998]

Published by Elsevier Science Inc. 1986; D'Amato et al. 1987; Zubenko et al. 1988), many cognitive dysfunction modeling studies have focused on this system (Beatty et al. 1986; Sunderland et al. 1987; Broks et al. 1988; Dunne 1990; Flicker et al. 1990; Sunderland et al. 1990; Molchan et al. 1992). An earlier report of a potential noninvasive test for $\mathrm{AD}$ using the cholinergic antagonist tropicamide (Scinto et al. 1994) and the ongoing clinical use of the anticholinesterase inhibitors tacrine and donepezil (Davis et al. 1992; Farlow et al. 1992; Knapp et al. 1994; Rogers et al. 1996) for the treatment of $\mathrm{AD}$ further highlight the importance of cholinergic neurons in AD.

Modeling studies involving the cholinergic system in humans have focused principally on the muscarinic system, but the nicotinic system is also important in cognition and AD (Whitehouse et al. 1986; Newhouse et al. 1992; Newhouse et al. 1994). In human autopsy studies, for example, there is a marked reduction of cortical nicotinic receptors in $\mathrm{AD}$ patients as compared to matched 
controls, in contrast to the findings with muscarinic receptors (Whitehouse et al. 1986; Nordberg et al. 1990; Perry et al. 1990; Nordberg et al. 1992; Kellar et al. 1987; Flynn and Mash 1986). Hence, we became interested in the combined effects of these two systems, specifically employing scopolamine as a centrally active muscarinic antagonist and mecamylamine as a nicotinic antagonist.

To our knowledge, mecamylamine and scopolamine have only been combined in one previous human study (Gitelman and Prohovnik 1992), which showed with ${ }^{133} \mathrm{Xe}$ inhalation methods that the nicotinic antagonist mecamylamine decreased perfusion in parietotemporal cortex, while the addiction of scopolamine reduced blood flow in frontal cortex. Because central blood flow in parietal and temporal cortex are known to be affected by AD (Haxby et al. 1988; Prohovnik et al. 1988; Friedland et al. 1989; Kumar et al. 1991), the blood flow pattern induced by scopolamine and mecamylamine together may more closely model AD than scopolamine alone. Because cognitive testing was limited, behavioral measurements were absent, and there was no placebo or scopolamine-alone condition in the Gitelman and Prohovnik study, speculations about the cognitive modeling of this combination were limited. Hence, the current study was initiated in normal elderly volunteers to determine whether combined muscarinic and nicotinic blockade would more closely mimic the cognitive, physiological, and behavioral deficits found in AD.

\section{METHODS}

\section{Subjects}

Written informed consent was obtained, and subjects were paid for their participation. Procedures were in accord with the ethical standards of the committee on human experimentation of the National Institute of Mental Health (NIMH). Eight elderly normal volunteers completed the study (five females and three males, mean age \pm standard deviation $[S D]=61.9 \pm 8.3$ years, mean weight $\pm \mathrm{SD}=80.8 \pm 7.8 \mathrm{~kg}$ ). Three additional normal volunteers were withdrawn from the study after they developed significant postural hypotension from mecamylamine (one female and two males, mean age \pm $\mathrm{SD}=70 \pm 5.6$ years, mean weight $\pm \mathrm{SD}=61.2 \pm 9.4$ $\mathrm{kg}$; one completed only the first study day, and two completed 2 study days). The eight subjects completing the study were well educated (years of education $\pm \mathrm{SD}=$ $15.5 \pm 3.5$ ), of superior intelligence (estimated verbal intelligence quotient $\pm \mathrm{SD}=121.0 \pm 4.2$ [Grober and Sliwinski 1991], and Wechsler Memory Scale-Revised \pm $\mathrm{SD}=121.5 \pm 15.7$, [Wechsler 1987]), and without evidence of cognitive dysfunction as assessed by a standard dementia screening instrument (Mattis Dementia Rating Scale score $\pm \mathrm{SD}=142.1 \pm 1.0$ ) (Mattis 1976).

Medical histories were obtained, physical and mental status exams were performed, and laboratory evaluations were completed to rule out medical and specific neuropsychiatric disorders. Individuals with a history of hypertension or cardiac illness were excluded from participation. Laboratory tests included electrocardiogram, chest X-ray, hematology and chemistry panels, urinalysis, HIV, hepatitis screen, rapid plasma reagin (RPR) tests, and thyroid function tests. Subjects were drug-free for at least 2 weeks before beginning the study except for one subject on stable, routine clinical doses of levothyroxine and one subject on stable postmenopausal doses of estrogen. All subjects were nonsmokers and were caffeine and alcohol free for at least 24 hours before study days.

\section{Procedures}

There were 4 study days separated by at least 72 hours for each subject. Subjects received four separate challenges: placebo, scopolamine, mecamylamine, and scopolamine + mecamylamine. As a safety measure against such possible medication side effects as hypotension, the first 2 study days included only placebo or mecamylamine alone. Only after subjects safely tolerated mecamylamine alone were they exposed to the combination of mecamylamine + scopolamine. Hence, subjects received mecamylamine or placebo for days 1 and 2, and scopolamine or scopolamine + mecamylamine for days 3 and 4 . The order of the medication administration within those parameters was randomized and balanced across subjects. Several subjects exposed to mecamylamine developed prolonged orthostatic hypotension and so were kept overnight on the research unit; for those subjects, the orthostatic blood pressure was normalized for least 72 hours before any further study days occurred.

After overnight fast, subjects reported to clinic at 8:00 A.M. for each study day. An intravenous catheter was placed in an antecubital vein in the nondominant arm at least $20 \mathrm{~min}$ before the first medication was administered. Medications were given orally or intravenously under double-blind randomized conditions. The dosing and timing of medications were chosen to optimize any possible cognitive effects, while minimizing physical side effects. Oral mecamylamine $0.2 \mathrm{mg} / \mathrm{kg}$ up to a maximum dose of $15 \mathrm{mg}$ (seven subjects received $15 \mathrm{mg}$ and one subject received $13.75 \mathrm{mg}$ ), or placebo was given after baseline vital signs and behavioral ratings had been determined (at $\mathrm{t} 1$ as shown in Figure 1). Sixty min after the PO medication (t2 in Figure 1), scopolamine $400 \mathrm{mcg}$ or $0.9 \%$ sodium chloride placebo was infused over $1 \mathrm{~min}$.

\section{Cognitive Testing}

The cognitive measures were chosen to examine cognitive domains known to be impaired in Alzheimer's disease; namely, explicit memory and learning, access to categorical knowledge in long-term memory, and simple reaction time (see Nebes 1992 for review). Testing began 75 minutes after the scopolamine/placebo infusion (135 min 


\section{Study Design}

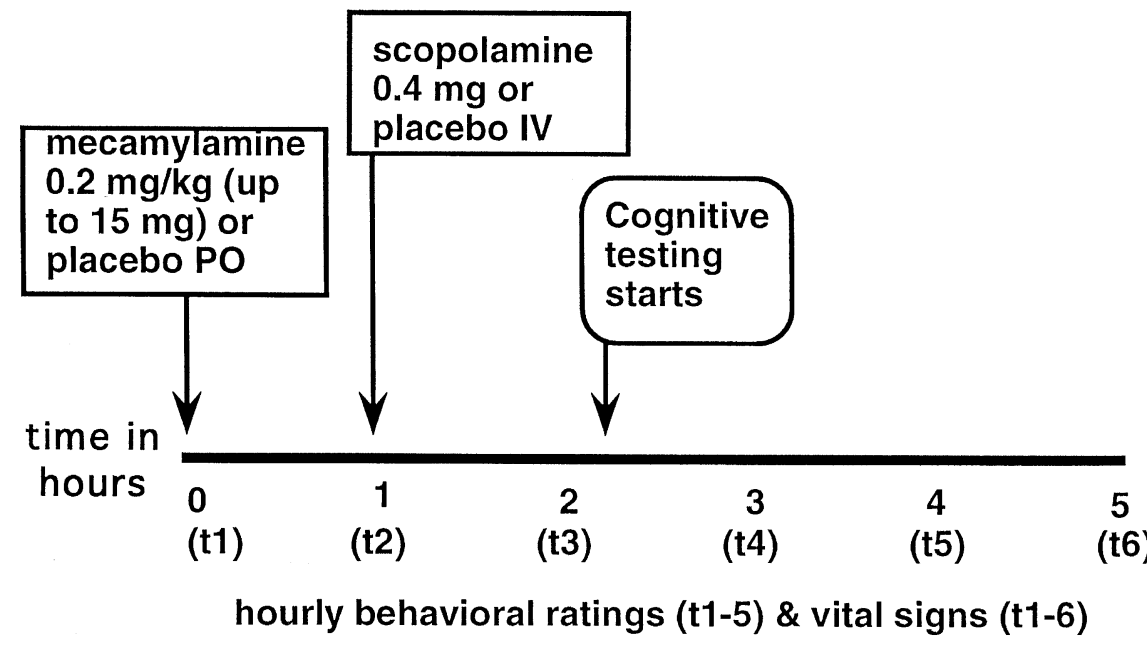

Figure 1. Study design for drugs and testing in combination challenge paradigm in elderly normal volunteers.

\section{4 study days for each subject $(n=8)$ : placebo, mecamylamine, scopolamine, scopolamine + mecamylamine}

after mecamylamine/placebo administration) and lasted about $30 \mathrm{~min}$. Five different versions of each task were created. Test versions were equated for word and name frequency (word list learning, [Kucera and Francis 1967] and the number of words retrieved (fluency tasks [Borkowski et al. 1967\}) based on published normative data. The different versions were randomized to create five unique test packets. Each subject participated in a practice session as well as the four drug conditions outlined above. The assignment of test packets was counterbalanced across drug administration days to avoid the possibility of form differences confounding the drug effects. The tests were administered in a fixed order for all sessions.

Explicit Memory and Learning. This was a promptedrecall, selective-reminding learning and memory procedure that has been frequently used as a method for assessing explicit memory functions (Buschke 1973). Each subject was presented a list of 12 unrelated common English words. The subject was then asked to remember as many of the words as possible. Words that were not remembered were repeated by the examiner and the subject was again asked to remember all of the words on the original list. Thus, the subject had to recall those words that were just read (the selectively prompted words) as well as the words previously recalled that were not presented again. This procedure was repeated for seven trials unless all of the words were successfully remembered for two consecutive trials. In this manner, the list learning mean (mean number of words recalled across trials), and the list learning mean consistency (mean consistency scores across trials) were calculated. The list learning consistency between two trials was defined as the number of words in a given trial correctly recalled without prompting divided by the number of words correctly recalled in the previous trial.
Semantic Memory. Access to categorical (structured) knowledge in long-term memory was tested by asking subjects to generate as many exemplars as possible within $60 \mathrm{sec}$ to a letter or category name. Subjects did this fluency task four times each session (two letters and two category names, such as parts of a building or types of fruit). One letter and category was repeated across sessions (fixed) and one was changed from session to session (variable).

Simple Reaction Time. This task consisted of 40 trials, wherein subjects were instructed to maintain visual fixation on a fixation cross, and then to press a button as quickly as possible when a large red disk appeared on the computer display. Each trial began with a fixation point that remained on the screen for a random period between 300 and 1700 milliseconds (ms). On 35 trials, the fixation point was replaced by a filled red circle that remained on the screen until a response was made or 3,500 ms elapsed. Five of the trials were catch trials, where no filled red circle (imperative stimulus) was presented. The dependent measures were reaction time to the imperative stimulus, omission error rate (percentage of trials that subjects did not respond to the disk), and commission error rate (percentage of trials that subjects responded during the catch trials or before the presentation of the disk).

\section{Behavioral Measures}

Behavioral and physiologic ratings were obtained at baseline and then throughout the study, as shown in Figure 1. Rating scales included: the National Institute of Mental Health Self-Rating Scale (Van Kammen and Murphy 1975; Murphy et al. 1989), a modified version 
of the Brief Psychiatric Rating Scale (BPRS) (Overall and Gorham 1962; Overall and Beller 1984), a physical symptom checklist containing 25 items rated on a scale of 0 to 3 for severity, and a visual analog scale for mood in which subjects indicated their overall mood on a 100$\mathrm{mm}$ scale in which 0 reflected the best mood ever.

\section{Physiologic Measures}

For clinical monitoring, vital signs were measured at baseline and then every $30 \mathrm{~min}$ during each study day. Figure 1 illustrates the hourly time points used for data analysis. Blood pressure and pulse were measured on an automated monitor. Oral temperature was measured on an automated digital thermometer, and pupil size was measured with a pupil gauge card. Patients were not allowed to get out of bed for the first 5 hours of the study, and then only if there were no clinically significant postural changes in blood pressure. It is noteworthy that some subjects developed significant postural changes in blood pressure at increments of $30^{\circ}$ (particularly after eating), so blood pressures were obtained whenever a position toward sitting up was increased by $30^{\circ}$ or more, and patients were closely observed when making positional changes away from being completely supine.

\section{Data Analysis}

Data were analyzed for overall treatment effect (scopolamine vs. placebo, mecamylamine vs. placebo, mecamylamine + scopolamine vs. scopolamine) across time by repeated-measures analysis of variance (ANOVA) with time $\times$ drug contrasts determined a priori. Statistical comparisons were limited, because paired comparisons were only examined when overall ANOVAs for variables were significant. Carryover effects between treatment conditions were initially tested by ANOVA and ruled out; therefore, order was dropped from further analysis. To remove any effects of baseline differences, delta values (time ${ }_{\times}$- baseline) were used for statistical analysis. For the sake of simplicity of explanation, mean values are given in the tables that follow from the \#4 test battery $(\mathrm{t} 4=120$ minutes after scopolamine infusion), as shown in Figure 1. The SAS GLM program (SAS Institute, Cary, NC) was utilized for data analysis.

\section{RESULTS}

\section{Cognition}

As expected, scopolamine impaired cognitive functioning on multiple tests such as list learning and processing speed. Of more interest is the finding of a trend toward increased impairment in episodic memory with the addition of mecamylamine to scopolamine as compared to scopolamine alone for these eight subjects. For other cognitive tasks (semantic memory, lexical search and retrieval, and processing speed), performance scores were generally lower with the addition of mecamylamine to scopolamine as compared to scopolamine alone, but these differences were not statistically significant (see Table 1).

Explicit Memory. Mean list learning and consistency performance changed across drug conditions for the eight subjects, as shown in Table 1. As expected, scopolamine alone produced a significant impairment in mean list learning and consistency $(p<.01)$. The addition of mecamylamine to scopolamine for the eight subjects produced a tend toward increased impairment for list learning consistency compared to scopolamine alone ( $p<.1$, see Figure 2a). When all 10 subjects were considered who completed the first 2 study days, episodic memory was significantly impaired after subjects received mecamylamine alone as compared to placebo for list-learning mean $(\mathrm{F}[1,9]=6.74, p=.029$, not shown in Table 1), and for list-learning consistency $(\mathrm{F}[1,9]=5.21, p=.048$, not shown in Table 1$)$.

Semantic Memory. The overall ANOVAs for fixed and variable category fluency were not significant for the eight subjects completing all 4 study days. However, a separate analysis including all 10 subjects completing the first 2 study days did show differences between mecamylamine alone and placebo. Namely, fixed category fluency was significantly reduced $(\mathrm{F}[1,9]=$ $5.41, p=.045)$, and variable category preservations increased $(F[1,9]=6.00, p=.037)$ after subjects received mecamylamine alone as compared to placebo (not shown in Table 1).

Lexical Search and Retrieval. Overall ANOVAs were not significant for fixed or variable letter fluency tasks with the eight subjects completing all 4 study days. However, when the 10 subjects completing the first 2 study days were analyzed, there was a trend toward increased preservations $(F[1,9]=3.86, p=.081)$ after mecamylamine was given alone as compared to placebo (not shown in Table 1).

Processing Speed. Scopolamine significantly increased simple reaction time as compared to placebo $(p<.01)$ and created a trend toward increased omission errors $(p<$ .1), as shown in Table 1.

\section{Behavioral Ratings}

As anticipated, significant behavioral effects of scopolamine as compared to placebo were seen across a number of measures. Further behavioral impairment was found with the addition of mecamylamine to scopolamine in such selected measures as the BPRS 24-item subscale and the NIMH-SRS anxiety subscale, as described below. Table 2 summarizes behavioral data by 
Table 1. Cognitive Effects in Eight Normal Elderly Volunteers Following Drug Administration on 4 Separate Days

\begin{tabular}{|c|c|c|c|c|c|c|}
\hline \multirow[b]{3}{*}{ Cognitive Task } & \multirow{2}{*}{\multicolumn{2}{|c|}{ Overall ANOVA }} & \multicolumn{4}{|c|}{ Drug Conditions } \\
\hline & & & \multirow[b]{2}{*}{ PLA } & \multirow{2}{*}{$\begin{array}{c}\text { SCO } \\
\text { (vs. PLA) }\end{array}$} & \multirow{2}{*}{$\begin{array}{c}\text { MEC } \\
\text { (vs. PLA) }\end{array}$} & \multirow{2}{*}{$\begin{array}{c}\mathrm{SCO}+\mathrm{MEC} \\
\text { (vs. SCO) }\end{array}$} \\
\hline & $F(3,21)$ & $p$ value & & & & \\
\hline \multicolumn{7}{|l|}{ Episodic memory } \\
\hline List learning mean (7 trials) & 19.13 & .001 & $9.5 \pm 0.4$ & $6.4 \pm 0.7^{* *}$ & $9.0 \pm 0.6^{+}$ & $5.7 \pm 0.4$ \\
\hline List learning mean consistency & 19.43 & .001 & $0.84 \pm 0.03$ & $0.51 \pm 0.07^{* *}$ & $0.76 \pm .05^{+}$ & $0.33 \pm 0.07^{+}$ \\
\hline \multicolumn{7}{|l|}{ Semantic memory } \\
\hline Fluency, variable category & 0.67 & NS & $14.3 \pm 1.5$ & $13.9 \pm 0.8$ & $12.1 \pm 1.6$ & $12.4 \pm 1.8$ \\
\hline Fluency, fixed category & 1.58 & NS & $16.0 \pm 2.0$ & $16.3 \pm 1.9$ & $14.5 \pm 2.0$ & $15.1 \pm 2.1$ \\
\hline \multicolumn{7}{|l|}{ Lexical search and retrieval } \\
\hline Fluency, variable letter & 1.17 & NS & $14.6 \pm 1.4$ & $14.6 \pm 1.7$ & $15.6 \pm 1.5$ & $12.9 \pm 1.9$ \\
\hline Fluency, fixed letter & 0.52 & NS & $17.6 \pm 1.3$ & $15.9 \pm 2.0$ & $16.8 \pm 1.5$ & $16.5 \pm 1.4$ \\
\hline \multicolumn{7}{|l|}{ Processing speed } \\
\hline Simple reaction time (ms) & 15.27 & .001 & $288 \pm 16$ & $355 \pm 18^{* *}$ & $299 \pm 24$ & $362 \pm 15$ \\
\hline Omission errors & 3.32 & .046 & $0.0 \pm 0.0$ & $1.1 \pm 0.5^{\dagger}$ & $0.0 \pm 0.0$ & $1.1 \pm 0.5$ \\
\hline Commission errors & 2.13 & NS & $0.0 \pm 0.0$ & $2.1 \pm 2.1$ & $0.0 \pm 0.0$ & $8.3 \pm 5.5$ \\
\hline
\end{tabular}

Values are mean \pm SEM. PLA $=$ placebo, $\mathrm{SCO}=$ scopolamine, $\mathrm{MEC}=$ mecamylamine. By repeated-measures analysis of variance, ${ }^{* *}=p<.01,{ }^{*}=$ $p<.05$, and ${ }^{\dagger}=p<.1$. Significance levels are noted for contrasts in: SCO column for SCO vs. PLA, MEC column for MEC vs. PLA, SCO + MEC column for SCO + MEC vs. SCO.

providing means at a consistent time (test battery \#4, or t4, as shown in Figure 1) across drug conditions for each measurement. Only those subscales that showed significant changes are presented in the table.

BPRS Factors. As shown in Table 2, scopolamine as compared to placebo increased impairment, and the total score 24 items $(p<.01)$, as well as anxiety/depression, total score 18 items, and mania $(p<.05)$, and anergia at a trend level $(p<.1)$. Interestingly, there were further increases in impairment for the mecamylamine + scopolamine condition as compared to scopolamine alone for the total score 24 items $(p<.01$, see Figure $2 b)$, and at trend levels for impairment, anxiety/depression, and total score 18 items $(p<.1)$. At $\mathrm{t} 3$ (test battery \#3 as shown in Figure 1), the mania subscale was increased with mecamylamine plus scopolamine as compared to scopolamine alone $(p<.05$, not shown in Table 2$)$. Mecamylamine alone as compared to placebo also produced a trend increase on total score 24 items at $44(p<.1)$.

NIMH Self-Rating Scale. As shown in Table 2, scopolamine produced a significant increase $(p<.05)$ in functional deficit score as compared to placebo, which further increased at a trend level $(p<.1)$ when mecamylamine was added. Anxiety also increased with the addition of mecamylamine to scopolamine as compared to scopolamine alone $(p<.05)$.

Visual Analog Mood Scale. The overall ANOVA was not significant, so individual drug comparisons were not considered.

\section{Physiologic Measures}

A variety of physiologic changes were seen when scopolamine and mecamylamine were administered indi- vidually and in combination, as described below. Table 3 summarizes these by providing means at a consistent time (test battery \#4, or t4) across drug conditions for each measurement. Only those subscales that showed significant changes are presented in the table.

\section{Vital Signs}

Pupil Size. This was significantly increased after scopolamine infusion as compared to placebo $(p<.01)$ at all time points measured. A further increase in pupil diameter resulted from the addition of mecamylamine to scopolamine as compared to scopolamine alone at $t 4(p<$ .01 , see Figure $2 \mathrm{~d})$. A trend toward increase $(p<.1)$ in pupil size also occurred with mecamylamine alone as compared to placebo at the same time point.

Systolic Blood Pressure. This decreased after the administration of mecamylamine as compared to placebo at $\mathrm{t} 5$ and $\mathrm{t} 6(p<.01$, not in Table 3$)$ and at a trend level at $\mathrm{t} 3(p<.1$, not in Table 3). Systolic blood pressure was significantly lower with the combination of mecamylamine and scopolamine as compared to scopolamine alone at all time points $(p<.01$ at $\mathrm{t} 3$ and $\mathrm{t} 5$, and $p<.05$ at 44 and t6). Systolic blood pressures for all drug conditions at t4-6 are shown in Figure 2c.

Diastolic Blood Pressure. This decreased with scopolamine as compared to placebo $(p<.01$, shown in Table 3 ), and at a trend level at t3 ( $p<.1$, not shown in Table 3). Diastolic blood pressure did not change with mecamylamine alone as compared to placebo, but did decrease with the combined mecamylamine and scopolamine condition as compared to scopolamine at $\mathrm{t} 3(p<$ .05 , not shown in Table 3). 
LIST LEARNING MEAN CONSISTENCY

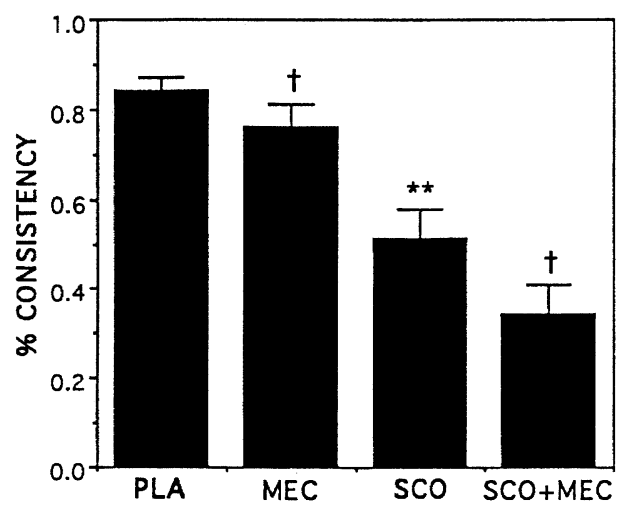

a.

SYSTOLIC BLOOD PRESSURE

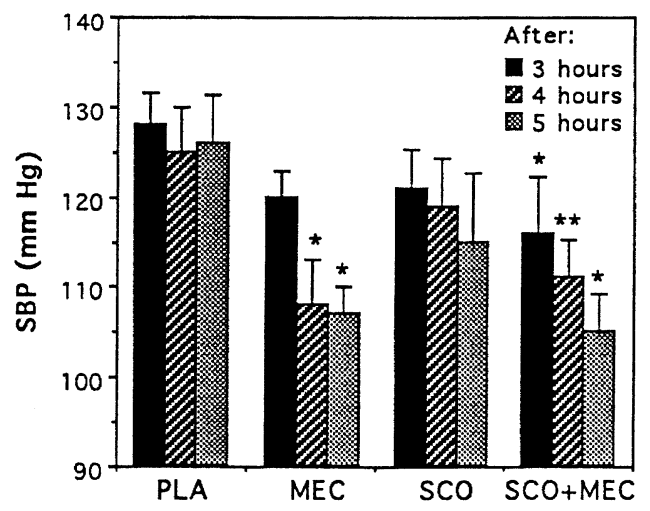

c.

\section{BPRS TOTAL SCORE (24 ITEMS)}

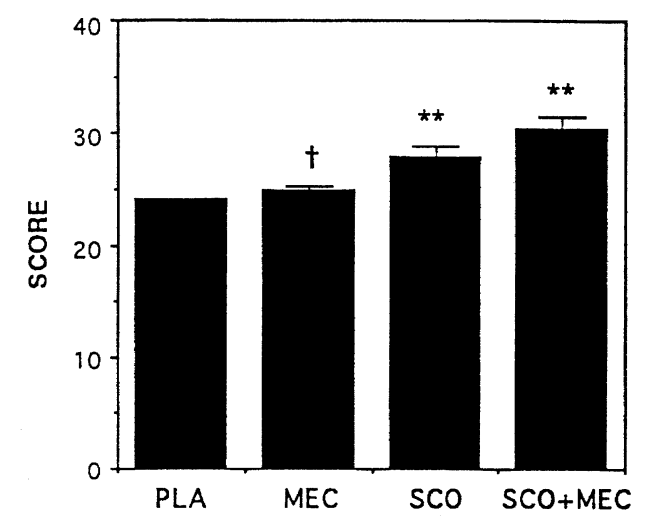

b.

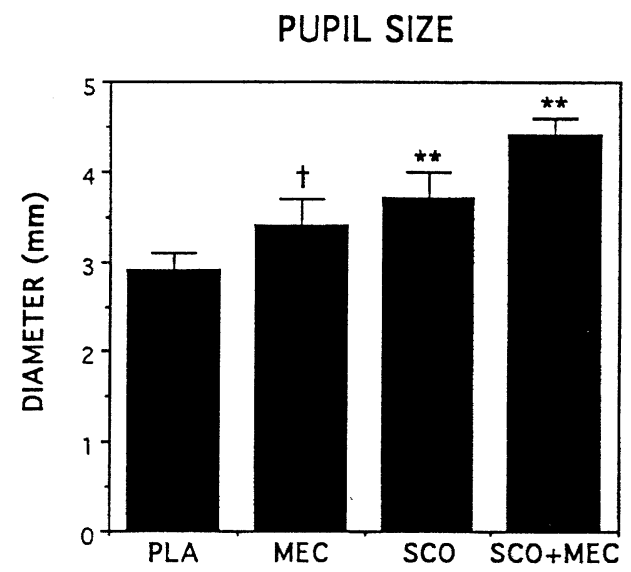

d.

Figure 2. Cognitive, behavioral, and physiologic variables in eight elderly normal volunteers across four drug conditions: Placebo (PLA) PO and IV, Mecamylamine (MEC) $0.2 \mathrm{mg} / \mathrm{kg}$ up to $15 \mathrm{mg}$ PO, Scopolamine (SCO) $0.4 \mathrm{mg}$ IV, and SCO+ MEC. Values are mean \pm SEM. $p$ values $\left({ }^{+}=p<.1{ }^{*}=p<.05,{ }^{* *}=p<.01\right.$ ) are given for drug condition contrasts (MEC vs. PLA, SCO vs. PLA, SCO + MEC vs. SCO) for: (a) list learning mean consistency \%; (b) total score 24 item of BPRS 3 hours after study day onset (t4) (c) systolic blood pressure 3-5 h after study day onset (d) pupil diameter in $\mathrm{mm} 3 \mathrm{~h}$ after study day onset ( $\mathrm{t} 4$ ).

Pulse. This decreased after scopolamine was given as compared to placebo at all time points $(p<.05)$. Conversely, pulse increased after mecamylamine was given as compared to placebo at $\mathrm{t} 3(p<.01$, not shown in Table 3$)$ and $t 4(p<.05)$. Pulse also increased with the combination of mecamylamine and scopolamine as compared to scopolamine alone at $\mathrm{t} 3-5(p<.01)$, and at t6 $(p<.05,5 \mathrm{~h}$ after the study began). (The overall ANOVAs for temperature and respiration were not significant.)

\section{Physical Symptoms}

The means for self-reported physical symptoms at $\mathrm{t} 4$ are given in Table 3. After scopolamine infusion as compared to placebo, dry mouth, tiredness, and drowsiness were increased $(p<.05)$. While scores for these symptoms increased further with the addition of mecamylamine to scopolamine, the differences were not statistically significant. At $\mathrm{t} 3$ (not shown in Table 3 ), there was a trend toward increase $(p<.1)$ in weakness with scopolamine as compared to placebo, and a trend toward decrease in weakness with mecamylamine + scopolamine as compared to scopolamine alone $(p<.1)$.

\section{DISCUSSION}

By combining the centrally active muscarinic blocker scopolamine with the nicotinic blocker mecamylamine, we have successfully generated a profile of cognitive impairments that may better mimic the cognitive pro- 
Table 2. Behavioral Ratings in Eight Normal Elderly Volunteers Across Three Different Scales Following Drug Administration on 4 Separate Days

\begin{tabular}{|c|c|c|c|c|c|c|}
\hline \multirow[b]{2}{*}{ Subscale } & \multicolumn{2}{|c|}{ Overall ANOVA } & \multicolumn{4}{|c|}{ Drug Conditions } \\
\hline & $\begin{array}{c}F(12,84) \\
\text { Drug } \times \text { Time }\end{array}$ & $p$ value & PLA & $\begin{array}{c}\text { SCO } \\
\text { (vs. PLA) }\end{array}$ & $\begin{array}{c}\text { MEC } \\
\text { (vs. PLA) }\end{array}$ & $\begin{array}{c}\text { SCO + MEC } \\
\text { (vs. SCO) }\end{array}$ \\
\hline \multicolumn{7}{|l|}{ BPRS factors } \\
\hline Anxiety/depression & 2.28 & .026 & $1.0 \pm 0.0$ & $1.1 \pm 0.1^{*}$ & $1.1 \pm 0.0$ & $1.3 \pm 0.1^{+}$ \\
\hline Anergia & 6.15 & .001 & $1.0 \pm 0.0$ & $1.3 \pm 0.1^{\dagger}$ & $1.1 \pm 0.1$ & $1.5 \pm 0.1$ \\
\hline Impairment & 15.35 & .001 & $1.0 \pm 0.0$ & $1.5 \pm 0.0^{* *}$ & $1.0 \pm 0.0$ & $1.8 \pm 0.2^{+}$ \\
\hline Mania & 7.84 & .001 & $1.0 \pm 0.0$ & $1.2 \pm 0.1^{*}$ & $1.0 \pm 0.0$ & $1.3 \pm 0.1$ \\
\hline Total score (18 items) & 6.62 & .001 & $18.1 \pm 0.1$ & $20.3 \pm 0.8^{*}$ & $18.8 \pm 0.3$ & $21.4 \pm 0.8^{\dagger}$ \\
\hline Total score (24 items) & 13.77 & .001 & $24.1 \pm 0.1$ & $27.8 \pm 1.0^{* *}$ & $24.9 \pm 0.3^{+}$ & $30.3 \pm 1.2^{* *}$ \\
\hline \multicolumn{7}{|l|}{ NIMH-SRS subscales } \\
\hline Anxiety & 3.82 & .008 & $0.3 \pm 0.3$ & $1.3 \pm 0.9$ & $0.3 \pm 0.3$ & $4.4 \pm 1.3^{*}$ \\
\hline Functional deficit & 8.69 & .001 & $0.4 \pm 0.4$ & $11.3 \pm 2.4^{* *}$ & $1.7 \pm 1.3$ & $17.9 \pm 3.8^{+}$ \\
\hline \multicolumn{7}{|l|}{ Visual analogue } \\
\hline Mood scale & 2.29 & .104 & $29.0 \pm 5.9$ & $39.0 \pm 6.5$ & $35.0 \pm 6.7$ & $42.0 \pm 8.2$ \\
\hline
\end{tabular}

All values are mean \pm SEM from the $t 4$ point $(180 \mathrm{~min}$ after MEC/PLA and $120 \mathrm{~min}$ after SCO/PLA). BPRS = Brief Psychiatric Rating Scale NIMH-SRS: National Institute of Mental Health Self-Rating Scale. PLA = placebo, SCO = scopolamine, MEC = mecamylamine. By repeated-measures analysis of variance, ${ }^{+}=p<.1{ }^{*}=p<.05$, and ${ }^{* *}=p<.01$. Significance levels are noted for contrasts in: SCO column for SCO vs. PLA, MEC column for MEC vs. PLA, and SCO + MEC column for SCO + MEC vs. SCO.

file of AD than either agent alone. Furthermore, behavioral and physiologic effects were also consistent with enhanced effects of the combination over either individual drug. Although previous work has demonstrated the blood flow effect of this combination (Gitelman and Prohovnik 1992), this paper presents the first doubleblind human study in which the cognitive, behavioral, and physiologic effects of combined scopolamine and mecamylamine administration were compared to the effects of the drugs individually.

A limitation of the study is the small sample size of eight subjects who completed all four drug conditions. This limitation surfaces, for example, when considering the trend level finding of increased impairment in list learning mean consistency with the addition of mecamylamine to scopolamine as compared to scopolamine alone. Rather than discarding this observation, however, we believe that the implications of this trend observation are important and should be considered for several reasons. First, this is a pilot study in a rather uncharted area. Second, as discussed later, both animal and the previous human data are consistent with the finding of increased cognitive impairment when nicotinic blockade is added to muscarinic blockade. Furthermore, increased impairment is also seen with the addition of mecamylamine to scopolamine across a number of other variables (behavioral and physiological), suggesting a broader, consistent effect of this drug combination as compared to scopolamine alone. Another possible concern regarding our study is that the data analysis considers a large number of variables without Bonferonni corrections. However, although a wide variety of dependent variables are considered in this study, statistical comparisons were, in fact, quite limited, because contrasts were determined a priori and were examined only when overall ANOVAs were significant.

Most importantly, our data suggest that mecamylamine + scopolamine generates additional cognitive impairment when compared to scopolamine alone and may, therefore, serve as a better model of AD than scopolamine alone. As reviewed by Molchan et al. (1992), scopolamine alone can produce deficits in elderly controls that overlap with some of the deficits seen in $A D$, such as impaired episodic memory, semantic memory, attention, and vigilance. In addition to replicating the bulk of those findings, we also found that mecamylamine alone can impair cognitive functioning in domains that are also affected in AD. Namely, with 10 subjects receiving mecamylamine alone as compared to placebo, we found deficits in episodic and semantic memory tasks. Although others have also found that mecamylamine alone produces cognitive impairment in normal volunteers (Stolerman et al. 1973; Newhouse et al. 1992) that increases with age (Newhouse et al. 1994), the previous human study examining the combined drugs found diminished performance on the Buschke Selective Reminding Test after scopolamine was added to mecamylamine (Gitelman and Prohovnik 1992). Unfortunately, the lack of a scopolamine-alone test condition in that experiment prevented the determination of whether the effect was attributable to scopolamine alone or the combined condition of scopolamine + mecamylamine. Our results, consistent with animal studies in which the co-administration of mecamylamine and scopolamine increased memory impairment (Levin et al. 1989, 1990; Riekkinen et al. 1990; Cozzolino 
Table 3. Physiologic Responses in Eight Normal Elderly Volunteers Following Drug Administration on 4 Separate Days

\begin{tabular}{|c|c|c|c|c|c|c|}
\hline \multirow[b]{3}{*}{ Subscale } & \multirow{2}{*}{\multicolumn{2}{|c|}{ Overall ANOVA }} & \multicolumn{4}{|c|}{ Drug Conditions } \\
\hline & & & \multirow[b]{2}{*}{ PLA } & \multirow{2}{*}{$\begin{array}{c}\text { SCO } \\
\text { (vs. PLA) }\end{array}$} & \multirow{2}{*}{$\begin{array}{c}\text { MEC } \\
\text { (vs. PLA) }\end{array}$} & \multirow{2}{*}{$\begin{array}{c}\text { SCO }+ \text { MEC } \\
\text { (vs. SCO) }\end{array}$} \\
\hline & Drug $\times$ Time & $p$ value & & & & \\
\hline Vital signs & $\mathrm{F}(15,105)$ & & & & & \\
\hline Pupil size (mm) & 9.41 & .001 & $2.9 \pm 0.2$ & $3.7 \pm 0.3^{* *}$ & $3.4 \pm 0.3^{+}$ & $4.4 \pm 0.2^{* *}$ \\
\hline Systolic BP & 2.11 & .018 & $128.0 \pm 3.6$ & $121.0 \pm 4.3$ & $120.0 \pm 2.9$ & $116.0 \pm 6.4^{*}$ \\
\hline Diastolic BP & 1.80 & .065 & $74.0 \pm 2.1$ & $69.0 \pm 2.3^{* *}$ & $69.0 \pm 3.0$ & $65.0 \pm 2.4$ \\
\hline Pulse/min & 3.12 & .002 & $64.0 \pm 2.4$ & $59.0 \pm 1.8^{*}$ & $70.0 \pm 2.4^{*}$ & $70.0 \pm 2.4^{* *}$ \\
\hline Physical symptoms checklist & $\mathrm{F}(12,84)$ & & & & & \\
\hline Dry mouth & 5.97 & .001 & $0.3 \pm 0.2$ & $1.4 \pm 0.3^{*}$ & $0.6 \pm 0.3$ & $1.8 \pm 0.3$ \\
\hline Tiredness & 3.57 & .005 & $0.0 \pm 0.0$ & $0.6 \pm 0.3^{*}$ & $0.6 \pm 0.3$ & $0.9 \pm 0.3$ \\
\hline Drowsiness & 5.66 & .001 & $0.0 \pm 0.0$ & $1.1 \pm 0.4^{*}$ & $0.3 \pm 0.2$ & $1.3 \pm 0.3$ \\
\hline
\end{tabular}

All values are mean \pm SEM from the $t 4$ time point $(180 \mathrm{~min}$ after MEC/PLA and $120 \mathrm{~min}$ after SCO/PLA). PLA $=$ placebo, SCO $=$ scopolamine, $\mathrm{MEC}=$ mecamylamine. By repeated-measures analysis of variance, ${ }^{* *}=p<.01,{ }^{*}=p<.05$, and ${ }^{\dagger}=p<.1$. Significance levels are noted for contrasts in: SCO column for SCO vs. PLA, MEC column for MEC vs. PLA, and SCO + MEC column for SCO + MEC vs. SCO.

et al. 1994), suggest that at least episodic memory may be more impaired with the drug combination than with either drug alone.

Interestingly, the behavioral and physiologic effects of combined mecamylamine and scopolamine administration as compared to scopolamine alone paralleled the cognitive effects, as shown in Figure 2. Behaviorally, significant increases were found for the BPRS total score (24 item) and NIMH-SRS anxiety subscale as well as trends for the BPRS factors of anxiety/depression, impairment, total score (18 item), and the NIMH-SRS functional deficit subscale, thus demonstrating that the addition of nicotinic blockade to muscarinic blockade increases behavioral impairment. At the same time, pupil size increased with both anticholinergic agents. Considering the finding of increased pupil dilation in response to the topical anticholinergic agent tropicamide in patients with probable AD vs. controls (Scinto et al. 1994), our finding of a further increase in pupil size with the addition of mecamylamine to scopolamine in healthy elderly controls models the cholinergic pupillary sensitivity seen in the AD patients. From a physiologic perspective, the changes in blood pressure and pulse with mecamylamine were not unexpected, considering its earlier development as a potent antihypertensive agent (Freis 1955; Freis and Wilson 1956; Moyer et al. 1957; Smirk and McQueen 1957). Of importance here, however, is that the subjects in this study maintained a supine position at least during the first 5 hours of the study (including during all cognitive testing) and that any blood pressure decreases while supine were not clinically significant.

Although mecamylamine is known to be a centrally acting nicotinic receptor antagonist with both competitive and noncompetitive properties (Martin et al. 1989; Takayama et al. 1989; Martin et al. 1990), the mechanism for nicotinic modulation of other cholinergic activ- ity is not fully elucidated. It has been hypothesized that nicotinic and muscarinic receptors may interact through synapses containing presynaptic nicotinic receptors and postsynaptic muscarinic receptors (Levin 1992). Furthermore, there is evidence for nicotinic presynaptic autoreceptors on cholinergic neurons (Lapchak et al. 1989a, b). This might account for the finding that mecamylamine produced a dose-dependent inhibition of brain $\left[{ }^{3} \mathrm{H}\right]$ acetylcholine synthesis that correlated with amnestic effects in rats, leading Elrod and Buccafusco (1991) to postulate that presynaptic nicotinic receptors may exert modulatory influence on cholinergic neurons.

In summary, this study was the first in humans to examine, in a controlled design, the cognitive, behavioral, and physiologic effects of the combined administration of scopolamine and mecamylamine as compared to the individual drugs alone. Our cognitive, behavioral, and physiologic data are consistent with an improved model for AD with this drug combination as compared to scopolamine alone and are consistent with preclinical, human, and autopsy studies demonstrating the important role that the nicotinic system plays in normal cognition and in such disease states as AD. Given the considerable molecular diversity of the nicotinic and muscarinic receptors (Decker et al. 1995; Brann et al. 1993; Wang et al. 1992) and the relative nonselectivity of mecamylamine and scopolamine, future modeling studies will benefit from the use of more selective pharmacologic agents.

\section{ACKNOWLEDGMENTS}

The authors thank Wilma Davis, Kathleen Dietrich, R.N., Charyl Staso, R.N., Julie Jaffe, Jeanne Radcliffe, R.N., and the nursing staff on NIH Clinical Center Nursing Unit 3 East for their help with this project. 


\section{REFERENCES}

Beatty WW, Butters N, Janowsky DS (1986): Patterns of memory failure after scopolamine treatment: Implications for cholingergic hypotheses of dementia. Behav Neural Biol 45:196-211

Borkowski JG, Benton AL, Spreen O (1967): Word fluency and brain damage. Neuropsychologia 5:135-140

Bowen DM, Allen SI, Benton JS, Goodhardt EA, Haan AM, Palmer NR, Sims NR, Smith CCT, Spillane JA, Esiri MM Neary D, Snowdeon JS, Wilcock GK, Davison AN (1983): Biochemical assessment of serotonergic and cholinergic dysfunction and cerebral atrophy in Alzheimer's disease. J Neurochem 41:266-272

Brann MR, Ellis J, Jorgensen H, Hill-Eubanks D, Jones SV (1993): Muscarinic acetylcholine receptor subtypes: Localization and structure/function. Prog Brain Res 98:121127

Broks P, Preston GC, Traub M, Poppleton P, Ward C, Stahl SM (1988): Modeling dementia: Effects of scopolamine on memory and attention. Neuropsychologia 16:685700

Buschke H (1973): Selective reminding for analysis of memory and learning. J Verb Learn Verb Behav 12:543-550

Coyle JT, Price DL, DeLong MR (1983): Alzheimer's disease: A disorder of cortical cholinergic innervation. Science 219:1184-1190

Cozzolino R, Guaraldi D, Giuliani A, Chiradi O, Ramacci MT, Angelucci L (1994): Effects of concomitant nicotinic and muscarinic blockade on spatial memory disturbance in rats are purely additive: Evidence from the Morris water task. Physiol Behav 56:111-114

D'Amato RJ, Zweig RM, Whitehouse PJ, Wenk GL, Singer HS, Mayeux R, Price DL, Snyder SH (1987): Aminergic systems in Alzheimer's disease and Parkinson's disease. Ann Neurol 22:229-236

Davies P, Verth AH (1978): Regional distribution of muscarinic acetylcholine receptor in normal and Alzheimer'stype dementia brains. Brain Res 138:385-392

Davis KL, Thal LJ, Gamzu ER, Davis CS, Woolson RF, Gracon SI, Drachman DA, Schneider LS, Whitehouse PJ, Hoover TM, Morris JC, Kawas CH, Knopman DS, Earn NL, Kumar V, Doody RS (1992): A double-blind, placebo-controlled multicenter study of tacrine for Alzheimer's disease. N Engl J Med 327:1253-1259

Decker MW, Brioni JD, Bannon AW, Arneric SP (1995): Diversity of neuronal nicotinic acetylcholine receptors: Lessons from behavior and implications for CNS therapeutics. Life Sci 56:545-570

Dunne MP (1990): Scopolamine and sustained retrieval from semantic memory. J Psychopharmacol 4:13-18

Elrod K, Buccafusco J (1991): Correlation of the amnestic effects of nicotinic antagonists with inhibition of regional brain acetylcholine synthesis in rats. J Pharmacol Exp Ther 258:403-409

Farlow M, Gracon SI, Hershey LA, Lewis KW, Sadowsky CH, Dolan-Ureno J (1992): A controlled trial of tacrine in Alzheimer's disease. JAMA 268:2523-2529

Flicker C, Serby M, Ferris SH (1990): Scopolamine effects on memory, language, visuospatial praxis, and psychomotor speed. Psychopharmacology 100:243-250

Flynn DD, Mash DC (1986): Characterization of L-[3H]nicotine binding in human cerebral cortex: Comparison between Alzheimer's disease and the normal. J Neurochem 47:1948-1954

Freis ED (1955): Mecamylamine in hypertension. Lancet 2:977

Freis ED, Wilson IM (1956): Mecamylamine, a new orally effective, hypotensive agent. Arch Intern Med 97:551561

Friedland RP, Jagust WH, Huesman RH, Koss E, Knottel B, Mathis CA, Ober BA, Mazoyer BM, Budinger TF (1989): Regional cerebral glucose transport and utilization in Alzheimer's disease. Neurology 39:1427-1434

Gitelman DR, Prohovnik I (1992): Muscarinic and nicotinic contributions to cognitive function and cortical blood flow. Neurobiol Aging 13:313-318

Grober E, Sliwinski M (1991): Development and validation of a model for estimating premorbid verbal intelligence in the elderly. J Clin Exp Neuropsychol 13:933-949

Haxby JV, Grady CL, Koss E, Horwitz B, Schapiro M, Friedland RP, Rapoport SI (1988): Heterogeneous anteriorposterior metabolic patterns in dementia of the Alzheimer type. Neurology 38:1853-1863

Kellar KJ, Whitehouse PJ, Martino-Barrows AM, Marcus K Price DL (1987): Muscarinic and nicotinic cholinergic binding sites in Alzheimer's disease cerebral cortex. Brain Res 436:62-68

Knapp MJ, Knopman DS, Solomon PR, Pendlebury WW, Davis CS, Gracon SI (1994): A 30-week randomized controlled trial of high-dose tacrine in patients with Alzheimer's disease. The Tacrine Study Group. JAMA 271: 985-991

Kucera H, Francis WN (1967): Computational Analysis of Present-Day American English. Providence, RI, Brown University Press

Kumar A, Schapiro MB, Grady C, Haxby JV, Wagner E, Salerno JA, Friedland RP, Rapoport SI (1991): High-resolution PET studies in Alzheimer's disease. Neuropsychopharmacology 4:35-46

Lapchak PA, Araujo DM, Quirion R, Collier B (1989a): Effect of chronic nicotine treatment on nicotinic autoreceptor function and $\mathrm{N}-\left[{ }^{3} \mathrm{H}\right]$ methylcarbamycholine binding sites in the rat brain. J Neurochem 52:483-491

Lapchak PA, Araujo DM, Quirion R, Collier B (1989b): Presynaptic cholinergic mechanisms in the rat cerebellum: Evidence for nicotinic, but not muscarinic autoreceptors. J Neurochem 53:1843-1851

Levin ED (1992): Nicotinic systems and cognitive function. Psychopharmacology (Berl) 108:417-431

Levin ED, McGurk SR, South D, Butcher LL (1989): Effects of combined muscarinic and nicotinic blockade on choice accuracy in the radial-arm maze. Behav Neural Biol 51:270-277

Levin ED, Rose JE, McGurk SR, Butcher LL (1990): Characterization of the cognitive effects of combined muscarinic and nicotinic blockade. Behav Neural Biol 53:103-112

Martin BR, Onaivi ES, Martin TJ (1989): What is the nature of mecamylamine's antagonism of the central effects of nicotine? Biochem Pharmacol 38:3391-3397 
Martin TJ, Suchocki J, May EL, Martin BR (1990): Pharmacological evaluation of the antagonism of nicotine's central effects by mecamylamine and pempidine. J Pharmacol Exp Ther 254:45-51

Mash DC, Flynn DD, Potter LT (1985): Loss of M2 muscarine receptors in the cerebral cortex in Alzheimer's disease and experimental cholinergic denervation. Science 228: 1115-1117

Mattis S (1976): Mental status examination for organic mental syndrome in the elderly patient. In Bellak L, Karasu TB (eds), Geriatric Psychiatry. New York, Grune \& Stratton, pp 77-121

Molchan SE, Martinez RA, Hill JL, Weingartner HJ, Thompson K, Vitiello B, Sunderland T (1992): Increased cognitive sensitivity to scopolamine with age and a perspective on the scopolamine model. Brain Res Rev 17:215-226

Moyer J, Heider C, Dennis E (1957): Mecamylamine (inversine) in the treatment of hypertension. JAMA 164:18791886

Murphy DL, Mueller EA, Hill JL, Tolliver RJ, Jacobsen FM (1989): Comparative anxiogenic, neuroendocrine, and other physiologic effects of $\mathrm{m}$-chlorophenylpiperazine given intravenously or orally to healthy volunteers. Psychopharmacology 98:275-282

Nebes RD (1992): Cognitive dysfunction in Alzheimer's disease. In Craik FIM, Salthouse TA (eds), Handbook of Cognitive Aging. Hillsdale, New Jersey, Lawrence Erlbaum Associates, pp 373-446

Newhouse PA, Potter A, Corwin J, Lenox R (1992): Acute nicotinic blockade produces cognitive impairment in normal humans. Psychopharmacology 108:480-484

Newhouse PA, Potter A, Corwin J, Lenox R (1994): Agerelated effects of the nicotinic antagonist mecamylamine on cognition and behavior. Neuropsychopharmacology 10:93-107

Nordberg A, Hartvig P, Lilja A, Viitanen M, Amberla K, Lundqvist $\mathrm{H}$, Andersson $\mathrm{Y}$, Ulin J, Winblad B, Langstrom B (1990): Decreased uptake and binding of ${ }^{11} \mathrm{C}-$ nicotine in brain of Alzheimer patients as visualized by positron emission tomography. J Neural Transm 2:215224

Nordberg A, Alafuzoff I, Winblad B (1992): Nicotinic and muscarinic subtypes in the human brain: Changes with aging and dementia. J Neurosci Res 31:103-111

Overall JE, Beller SA (1984): The brief psychiatric rating scale (BPRS) in geropsychiatric research: I. Factor structure on an inpatient unit. J Gerontol 39:187-193

Overall JE, Gorham DR (1962): The brief psychiatric rating scale. Psychol Rep 10:799-812

Perry EK, Smith CJ, Court JA, Perry RH (1990): Cholinergic nicotinic and muscarinic receptors in dementia of Alzheimer, Parkinson, and Lewy body types. J Neural Transm 2:149-158

Prohovnik I, Mayeux R, Sackheim HA, Smith G, Stern Y, Alderson PO (1988): Cerebral perfusion as a diagnostic marker of early Alzheimer's disease. Neurology 38:931-937

Riekkinen PJ, Sirvio J, Aaltonen M, Riekkinen P (1990): Effects of concurrent manipulations of nicotinic and muscarinic receptors on spatial and passive avoidance learning. Pharmacol Biochem Behav 37:405-410

Rogers SL, Friedhoff LT, and the Donepezil Study Group (1996): The efficacy and safety of donepezil in patients with Alzheimer's Disease: results of a US multicentre, randomized, double-blind, placebo-controlled trial. Dementia 7:293-303

Scinto LF, Daffner KR, Dressler D, Ransil BI, Rentz D, Weintraub S, Mesulam M, Potter H (1994): A potential noninvasive neurobiological test for Alzheimer's disease. Science 266:1051-1054

Shimohama S, Taniguchi T, Fjuiwara M, Kameyama M (1986): Changes in nicotinic and muscarinic cholinergic receptors in Alzheimer-type dementia. J Neurochem 46:288-293

Smirk FH, McQueen EG (1957): Use of mecamylamine in the management of hypertension. Br Med J 422-425

Stolerman IP, Goldfarb T, Fink R, Jarvik ME (1973): Influencing cigarette smoking with nicotine antagonists. Psychopharmacologia 28:247-259

Sunderland T, Molchan SE, Martinez RA, Vitiello B, Martin P (1990): Drug challenge strategies in Alzheimer's disease: A focus on the scopolamine model. In Becker RE, Giacobini E, (eds), Alzheimer's Disease: Current Research in Early Diagnosis. New York, Taylor \& Francis Publishers, pp 173-181

Sunderland T, Tariot PN, Cohen RM, Weingartner H, Mueller EA, Murphy DL (1987): Anticholinergic sensitivity in patients with dementia of the Alzheimer type and agematched controls: A dose-response study. Arch Gen Psychiatry 44:418-426

Sunderland T, Tariot PN, Weingartner H, Murphy DL, Newhouse PA, Mueller EA, Cohen RM (1986): Pharmacologic modeling of Alzheimer's disease. Prog NeuroPsychopharmacol Biol Psychiatry 10:599-610

Takayama H, Majewska MD, London ED (1989): Interactions of noncompetitive inhibitors with nicotinic receptors in the rat brain. J Pharmacol Exp Ther 253:1083-1089

Van Kammen DP, Murphy DL (1975): Attenuation of the euphoriant and activating effects of $\mathrm{d}$ - and l-amphetamine by lithium carbonate treatment. Psychopharmacolgia 44:215-224

Wang S-Z, Zhu S-Z, Mash DC, El-Fakahany EE (1992): Comparison of the concentration of messenger RNA encoding four muscarinic receptor subtypes in control and Alzheimer brains. Molec Brain Res 16:64-70

Wechsler D (1987): Wechsler Memory Scale-Revised Manual. San Antonio, TX, The Psychological Corp., Harcourt Brace, Inc.

Whitehouse PJ, Au KS (1986): Cholinergic receptors in aging and Alzheimer's disease. Prog Neuro-Psychopharmacol Biol Psychiatry 10:665-676

Whitehouse PJ, Martino AM, Antuono PG, Lowenstein PR, Coyle JT, Price DL, Keller KJ (1986): Nicotinic acetylcholine binding sites in Alzheimer's disease. Brain Res 371:146-151

Zubenko GS, Moossy J, Hanin I, Martinez AJ, Rao GR, Kopp U (1988): Bilateral symmetry of cholinergic deficits in Alzheimer's disease. Arch Neurol 45:255-259 